\title{
IDENTIFICATION OF TECHNOLOGICAL STRUCTURES USING PATENT STATISTICS*
}

by

Michael K. Fung ${ }^{\dagger}$ and William W. Chow

${ }^{*}$ This project is supported by the Center for Economic Development, HKUST.

$\dagger$ 'Corresponding author. Hong Kong Polytechnic University, Hung Hom, Kowloon, Hong Kong. email: bumikef@polyu.edu.hk

${ }^{\ddagger}$ Department of Economics and Center for Economic Development, Hong Kong University of Science and Technology, Clearwater Bay, Kowloon, Hong Kong. email: eccwy@ust.hk 
Brief Title: Identification of Technological Structures 


\begin{abstract}
This paper explores the use of patent statistics in identifying four aspects of technological structure, namely, the potential knowledge pool, cumulativeness, inter-firm homogeneity in technology levels, and the scope of innovations. The firms studied are sampled from the chemical (CHEM), the computer (COM) and the electrical and electronic (EE) industries worldwide. We find that the contributions of intraindustry spillover are low at $12 \%, 10 \%$, and $9 \%$ for the three industries respectively. In addition, they can internalize $15 \%, 19 \%$ and $13 \%$ of their previous research efforts respectively. Fundamental innovations are relatively more important to the development of CHEM and less so for the other two industries. Lastly, we show that the results of empirical tests lend support to our specifications of these proxies.
\end{abstract}

JEL classification No.: O310, O330, L100.

Key words: Innovation, Technological Structure, Patent Citation. 


\section{LIST OF FIGURES}

Fig. 1 Two-firm and Three-firm Common Citation Indices

Fig. 2 Intra-industry Intensity of Knowledge Flow and Cumulativeness

Fig. 3 Technology Level Homogeneity and Scope of Innovations

Fig. 4 Herfindahl Indices based on Number of Patents 


\section{INTRODUCTION}

Economists have long used patent data to answer such questions as relationship between technological change and economic growth, the effects of different market structures and institutional arrangements on innovation, and the like. The practice of measuring innovation by patent numbers seems natural and has been widely adopted. For instance, the intensity of patent citations has been used to measure the significance of innovations, and the flow of citations used to proxy knowledge spillovers across technological, organizational and geographical boundaries. Griliches (1990) provides a comprehensive survey of the use of patent statistics in economic research.

This paper explores the use of patent and patent citation data to proxy four aspects of technological structure, namely, the potential knowledge pool (S1), the cumulativeness of knowledge from previous research (S2), inter-firm homogeneity of technology levels (S3), and the scope of innovations (S4). We compile various indices using patent data obtained from the United States Patent and Trademark Office (USPTO) to identify those attributes in three distinct industries: the chemical in-

dustry (CHEM), the computer industry (COM), and the electrical \& electronic (EE) industry. These industries are chosen because they are among the ones with the 
largest number of patents granted in the U.S. ${ }^{1}$. The list of major firms in our sample can be found in Hoover's Online ${ }^{2}$ and is stipulated in the Appendix for reference. Some thoughts are given to the issue of striking a balance between enlisting a reasonable representation of those industries and maintaining a manageable sample size. We decided to confine our study to the following sub-sectors:

- CHEM: diversified chemical products,

- COM: personal computers, large-scale computers, data storage devices, computer softwares,

- EE: consumer electronics, durable electrical appliances.

with sample sizes of 70,77 and 77 for CHEM, COM and EE respectively.

The sample period of our analysis runs from 1976 to 1997. Non-U.S. firms are included in our sample because of their weights in R\&D activities. According to USPTO (2000), inventors with U.S. origin and foreign origin accounted for $58 \%$ and $42 \%$ of the total patents granted respectively in 1997. Our sample includes patents granted to corporations only since they are the major patentees. USPTO (2000) reports that $83 \%$ of the patents issued in 1997 belongs to corporations with only $16 \%$

\footnotetext{
${ }^{1}$ The leaders include industrial chemicals, computers, mechanical instruments, drugs, rubber and plastic products, and communication equipment.

${ }^{2}$ http://www.hoovers.com/
} 
belonging to individuals. Moreover, the top 400 patenting firms alone accounted for $60 \%$ of the patents granted that year, while the 224 firms in our sample accounted for $19 \%$ of the total. Judged from this figure, the breadth of our sample should be large enough to generate reliable results.

\section{MEASURING THE FOUR ASPECTS OF TECHNOLOGICAL STRUC- TURE}

\subsection{Potential knowledge pool (S1)}

An important issue in the economics of $R \& D$ is to quantify $R \& D$ spillovers, or more specifically, the induced benefits that an inventor receives from innovations of others. One natural solution is to trace the linkage between two inventions across time as established by references or citations. Jaffe et al. (1993) offers a brief discussion on how patents are examined and relevant citations manifested. Althought these citation flows come in handy when measuring knowledge spillover, they should be used with caution. A recent survey by Jaffe et al. (2000) shows that about half of the patent citations truly represent the knowledge flows perceived by citing inventors themselves. In other words, only half of the total backward citations ${ }^{3}$ can really generate knowledge flows that are useful to the citing innovators, with the rest purely due to the judgements of patent examiners. In addition, they find a significant differ-

\footnotetext{
${ }^{3}$ The quoting of historical patents by the citing inventors and/or the patent examiners.
} 
ence in spillover scores between actual citations and "placebo" 4 citations. Therefore, they conclude that aggregate citation flows could be used as proxies for knowledge spillover, but the "noises" in those data have to be filtered out before meaningful interpretations can be made.

Another way to capture knowledge flows among firms and industries is to classify firms into different technological clusters according to the technological classifications of their patents. Jaffe (1988), for instance, relies on the Patent Office's Classification system to identify the proximity of firms in the technology space. Proximity between two firms measures the degree of overlap or duplication in their research interests. Hence, a relevant spillover pool pertinent to a firm can be constructed by summing up the R\&D efforts of all the other firms weighted by their proximity.

Our approach here is to look at the potential knowledge pool at the industry level. This is equivalent to grouping firms into different technological clusters according to the types of products they produce. A similar study has been done by Scherer (1981) in which he constructs an "inter-industry technology flows matrix" to examine the knowledge flows between different industries. A major finding of Scherer is that the benefits of R\&D embodied in intermediate goods purchased by an industry is an

\footnotetext{
${ }^{4}$ Patents that are not cited by the inventors, but are selected from the same patent class and included in questionaires as one of the actually cited patents.
} 
important determinant of productivity growth ${ }^{5}$. In some instances, the significance of this simply outweighs the impact of the industry's own R\&D. This result is in line with the view of Schmookler (1966).

In order to separate the spillover pools within and outside an industry, we construct two measures from the citation data, namely, the technological overlap between firms and the inter-industry intensity of knowledge flows. The first measure, overlap in research area $(O L)$ in industry $j$ is measured by the $k$-firm common citation index, which is defined as follows:

$$
O L_{k, j, t}=C P_{k, j, t} / P T_{j, t}
$$

where $C P_{k, j, t}$ is the number of patents that have been commonly cited by $k$ or more firms in industry $j$ at time $t$; and $P T_{j, t}$ is the number of patents granted to industry $j$ at time $t$. Notice that those patents counted in compiling $O L_{k, j, t}$ may have orientations other than industry $j$. The ratio $O L_{k, j, t}$ neutralizes the intensity of citation due to differences in the size of the patent pools in various industries ${ }^{6}$. When compiling the index, any patent that appears in the list of backward citations is counted once regardless of its citation frequency.

The second measure, inter-industry intensity of knowledge flow $(I F)$ of firm $i$ in

\footnotetext{
${ }^{5}$ Embodied R\&D benefit is the improvement in the quality of producer goods that results from the R\&D efforts made by the manufacturers of those equipment.

${ }^{6}$ The specifications of other variables are rooted on the same argument.
} 
industry $j$ is defined as:

$$
I F_{i, j, t}=B C_{i, j, t} / P T_{i, j, t}
$$

where $B C_{i, j, t}$ is the number of times firm $i$ cited patents owned by other firms in industry $j$ (inter-industry backward citations), and $P T_{i, j, t}$ is the number of patents granted to firm $i$ of industry $j$ at time $t$. According to this definition, the citing firm $i$ and the cited firms $\neq i$ are all members of industry $j$, and $I F_{i, j, t}$ measures the intensity of knowledge flows accessible to firm $i$ due to efforts of all non $i$ firms in $j$. Apparently, this measure supposes a priori that firms producing similar products are the major beneficiaries of knowledge spillovers surrounding them.

From $I F_{i, j, t}$, we can also derive another variable to measure the inter-industry intensity of knowledge flow $(E F)$ associated with firm $i$ :

$$
E F_{i, j, t}=\left(1 / P T_{i, j, t}\right)\left(T B C_{i, j, t}-B C_{i, j, t}-S C_{i, j, t}\right)
$$

where $T B C_{i, j, t}$ is the total number of backward citations made by firm $i$ at time $t$, and $S C_{i, j, t}$ is the number of times firm $i$ cited patents it owns. $E F_{i, j, t}$ measures the intensity of knowledge flow from industries other than $j$ to firm $i$. These other non $j$ firms could be either upstream firms that supply producer goods to firm $i$, or firms that produce a totally unrelated product. The measure aims to capture Schmookler's notion of inter-industry knowledge flow, the significance of which is confirmed by Griliches and Lichtenberg's (1984) study. 
Since the calculations of $O L_{k, j, t}$ and $I F_{i, j, t}$ involve screening through the entire pool of patents granted to industry $j$ and tracing every single backward citation made by each firm, we restrict the group of citing firms to a subset of all firms. The selection of the subset is based on Fortune 500 (1999) which ranks firms according to their revenues. As a result, we select 22, 24 and 18 firms from CHEM, COM and EE, respectively. For $C P_{k, j, t}, B C_{i, j, t}$ and $S C_{i, j, t}$, all backward citations made by the selected firms in $j$ at $t$ between 1983-1997 are screened. The corresponding pool of cited patents includes those granted in all years from 1976 to $t$. The number of backward citations made within the period $1983-1997$ by the 64 selected firms is $1,229,079$ and the number of patents granted to the 3 industries (the entire sample, i.e., all the 224 firms within the period 1976-1997) is 73,228 . The values of $O L_{k, j, t}$ and $I F_{j, t}$ at the industry level ${ }^{7}$ are given in Figures 1 and 2(a) below.

$$
\text { ** insert Figures } 1 \text { and } 2 \text { here }{ }^{* *}
$$

\subsection{Cumulativeness (S2)}

Cumulativeness represents the internal accumulation of knowledge of the innovating firms. An innovator usually builds up its internal knowledge base over time during the process of innovative activities. This knowledge base is internal to the innovator in the

\footnotetext{
${ }^{7}$ All components will be aggregated over $i$ to obtain figures at the industry level. For instance, $B C_{j, t} \equiv \sum_{i} B C_{i, j, t}$ and $P T_{j, t} \equiv \sum_{i} P T_{i, j, t}$ will be used for constructing $I F_{j, t}$. The aggregation of other variables is done analogously.
} 
sense that it cannot be imitated or can be imitated only through some learning-bydoings. Thus, cumulativeness indicates a firm's capability of internalizing the values of its knowledge and practical experience in future research. As a result, technology leaders usually enjoy higher cumulativeness than their followers do. According to Malerba and Orsenigo (1995), cumulativeness implies that leading innovators have an edge over the laggards and the former may continue to lead in the future. This is reasonable because firms that are continuously active in certain areas of research can accumulate knowledge and expertise that give them strong footings in those niches. The measure of cumulativeness $(C U)$ for firm $i$ at time $t$ is defined as follows:

$$
C U_{i, j, t}=S C_{i, j, t} / P T_{i, j, t}
$$

where $S C_{i, j, t}$ and $P T_{i, j, t}$ are as defined in the previous subsection. Figure 2(b) graphs the scores of $C U_{j, t}$ for each industry.

\subsection{Homogeneity in the levels of technology (S3)}

S3 indicates how close the technological levels of firms are within an industry. A small degree of homogeneity in technological levels indicates the existence of technology leaders. For instance, the findings of Malerba and Orsenigo (1995) show that technology leaders exist in the electricals and electronics, medical and chemical industries in Western Europe, but no evidence of such existence can be found in the mechanical and textile industries. 
A possible use of S3 is to investigate the differences in inventiveness of leveled and unleveled industries as suggested by Aghion et al. (1995). In a leveled industry, firms have more or less the same level of technology. Aghion et al. (1995) replaces the leap-frogging assumption of the basic Schumpeterian model by a more realistic "stepby-step" assumption. The catch is that some new knowledge created by innovators cannot be duplicated by rivals in the absence of the latter's own research effort. This implies, in essence, that two opposing forces are driving the innovation process and which one applies depends on the market environment. On the one hand, intense product market competition reduces the technology followers' incentive to innovate by reducing the profit potential of catching-up firms. On the other hand, competition encourages firms with similar technological levels to innovate because neck-to-neck competition results in slim profit margins for non-innovators. Thus, product market competition is conducive to innovative activities when there is a leveled technological environment, and the opposite is true when there is technological heterogeneity.

As is known from past literature, market concentration alone is insufficient in explaining the diversity of inventiveness across industries unless their technology concentration is also accounted for. With patent data, we can construct an index to measure the homogeneity in the levels of technology $(H O)$ among firms in industry $j$ as follows:

$$
H O_{j, t}=\left(\text { std dev. }\left[P T_{i, j, t}\right] / \text { mean }\left[P T_{i, j, t}\right]\right)^{-1}
$$




$$
=\mathcal{E}\left(P T_{i, j, t}\right) /\left(\mathcal{E}\left(P T_{i, j, t}-\mathcal{E}\left(P T_{i, j, t}\right)\right)^{2}\right)^{1 / 2}
$$

The expectation operator $\mathcal{E}$ in (5) is taken over $i$, i.e., all the firms in industry $j$ at time $t$. In the definition above, the standard deviation is normalized by the mean value to adjust for the difference in the number of patents granted. A high score of $H O_{j, t}$ indicates a high degree of homogeneity in the levels of technology within the industry, and vice versa. Figure $3(\mathrm{a})$ shows the values of $H O_{j, t}$ for each sample industry.

$$
\text { ** insert Figure } 3 \text { here }{ }^{* *}
$$

\subsection{Scope of innovations (S4)}

The measure S4 tells the relative importance of fundamental innovations and secondary innovations in the technological development of an industry. In reality, however, the distinction between fundamental and secondary innovations is often vague and can only be defined in a relative sense. For example, the invention of semiconductors can be considered as fundamental in computer technology, but it is secondary when compared to the discovery of silicon's chemical reaction to electromagnetic energy. That is to say, while some innovations are more fundamental in the sense that they open up opportunities for creating more future innovations, some are secondary because their emergence depends very much on previous innovations but is not crucial to the development of others. Therefore, fundamental innovations 
are expected to generate a wider scope of potential applications when compared to secondary innovations.

In this study, we use the U.S. Patent Classification (USPC) scheme to proxy for the scope of innovations. The larger the number of subclasses to which the USPTO assigns a particular patent, the more fundamental is the innovation associated with that patent, i.e., a wider scope of potential applications for that patent. A related study is by Lerner (1994) who found that patents assigned to more four-digit patent subclasses are more likely to be cited in subsequent patent documents and to be litigated for infringements.

The patent classification process adopted by the USPTO is as follows: a primary supervising examiner reviews an incoming patent application and assigns it to some of the 100,000 strong USPC subclasses. At the same time, the examiner also assigns the patent to one or more International Patent Classification (IPC) subclasses. According to a review of the two classification systems by Lerner (1994), the U.S. system is based primarily on structures and functions while the IPC emphasizes economic importance. Thus, with a technical focus, the USPC is the more appropriate scheme to distinguish between fundamental innovations and secondary innovations. We define the following measure of the scope of innovations $(S O)$ of firm $i$ in industry $j$ at time $t$ :

$$
S O_{i, j, t}=\left(\sum_{s=1}^{P T_{i, j, t}} C O_{s, i, j, t}\right) / P T_{i, j, t}
$$


where $C O_{s, i, j, t}$ is the number of USPC subclasses to which the USPTO assigns the $s$-th patent obtained by firm $i$ in industry $j$ at time $t$. The aggregate values $S O_{j, t}$ are shown in Figure 3(b).

\section{EMPIRICAL RESULTS}

Figure 1(a) plots the two-firm common citation indices as defined in equation (1) for each industry. COM has the largest number of (normalized) common citations while those of EE and CHEM are similar. Hence, the degree of technological overlap between firms is largest in the computer industry. The annual averages of the twofirm common citation indices over 1983-1997 are 0.41 for COM, 0.22 for CHEM and 0.25 for EE. The index for the computer industry exhibits what could be a trend break in early '90s, with growth becoming more drastic thenceforth. This indicates that research areas of computer firms are less diversified in the '90s, a phenomenon not witnessed in the other two industries. This might not be too surprising given the scramble for internet dominance before the turn of the century. Figure 1(b) plots the three-firm indices which show a similar pattern.

Figure 2(a) plots the intra-industry intensity of knowledge flow, $I F_{j, t}$, for each of the three industries. The diagram suggests that CHEM has the highest level of intensity, EE has the lowest and COM somewhere in between. The 1983-1997 averages are 0.79 for COM, 0.89 for CHEM, and 0.56 for EE. In other words, the chemical indus- 
try is almost $60 \%$ and $13 \%$ more dependent on intra-industry knowledge spillovers as compared to EE and COM respectively. All three industries, however, experienced a steady growth trend in $I F$ over the period. We can also get some insights about the relative importance of various sources of spillover by cross-referencing $I F_{j, t}$ with $E F_{j, t}$. The latter yields averages of 5.19 for COM, 5.46 for CHEM and 4.92 for EE, indicating that benefits of inter-industry spillover are more significant than those generated within the same industry.

The above results are consistent with Scherer's (1981) findings that a large proportion of knowledge spillover in a particular industry has origins in other industries. This kind of knowledge spillover from an external source can be generated either through the purchase of improved producer goods or by adopting the scientific knowledge produced by the other sectors. Having said that, $E F_{j, t}$ might have been biased upward by the limited amount of manufacturing industries in our sample. The interindustry knowledge pool is supposedly larger for a narrower definition of industrial categories. For instance, we narrowly define the computer industry as comprising personal computers, large scale computers, softwares and storage devices. Thus, a large proportion of knowledge flow to the computer industry originating from other related industries, such as semiconductors and computer electronics, may show up in the figures $E F_{j, t}$.

If the intra-industry intensity of knowledge flow, $I F_{j, t}$, is a correct measure of 
technological spillover, it should be positively related to the technological overlap, $O L_{k, j, t}$, between firms in that industry. This is because similarity of research areas implies that intra-industry spillover is more likely. In order to validate this conjecture between $I F_{j, t}$ and $O L_{k, j, t}$, we run a regression of the former on the latter and the results are given in Table 1.

\section{** insert Table 1 here**}

Notice that the variables of interest are log-transformed. As such, instead of using $I F_{j, t}$ and $O L_{k, j, t}$, we regress $\log B C_{j, t}$ on $\log C P_{k=2, j, t}$ together with a time-trend and industry-specific dummies. The $\log P T_{j, t}$ on both sides can be cancelled out by virtue of log-transformation. The specification is a standard fixed-effects panel data model and estimation by can be performed using the LSDV estimator, see for instance Mátyás and Sevestre (1996). Column two of the table lists the LSDV estimates. In view of the mild serial correlation evidenced in the disturbance term, an adjustment process $^{8}$ suggested by Bhargava et al. (1982) is used to tranform the data before running the Ordinary Least Squares. The result is summarized in column three of Table 1. As evidenced in Table 1, the positive relationship between $\log B C_{j, t}$ and $\log C P_{k=2, j, t}$ is both statistically significant and robust to our specifications. Indeed, the elasticity of $B C_{j, t}$ with respect to changes in $C P_{k=2, j, t}$ is about 0.56 . The significance of the time trend indicates that either exogenous technological growth or

\footnotetext{
${ }^{8}$ See Appendix A.2 for details.
} 
changes in the patent office's practices in drafting citations is a possible explanation for the upward trend of $I F_{j, t}{ }^{9}$.

Figure 2(b) shows the cumulativeness of firms in the three industries graphically. From the figure, we find that COM has the largest degree of cumulativeness, followed by CHEM and EE. The mean values of $C U_{j, t}$ over the period 1983-1997 are 1.45 for COM, 1.16 for CHEM and 0.82 for EE. These figures exceed their $I F_{j, t}$ counterparts as expected. Moreover, when compared to $T B C_{j, t} / P T_{j, t}$, we observe that about $20 \%$ of the patents cited by computer firms were owned by the citing inventors themselves. If we interpret self-citations as a proxy for cumulativeness, the figures suggest that firms in the computer industry were able to internalize about $20 \%$ of their research output on average in subsequent innovation. The figures for CHEM and EE, meanwhile, are $15 \%$ and $13 \%$, respectively. The results here are generally consistent with the findings of Malerba and Orsenigo (1995) which assert that chemicals, computers and electronics are characterized by a stable hierarchy of innovators, low birth rates of new innovators and large firm sizes.

Figure 3(a) suggests that the homogeneity in technology levels between firms is quite low for all the three industries. The standard deviations of the number of

\footnotetext{
${ }^{9}$ The latter is related to the "R\&D productivity puzzle", an anomaly regarding the tremendous growth in backward and forward citations in 1980s. Please refer to Lanjouw and Schankerman (1999) for further details.
} 
patents range between one to two times of the mean values. In other words, the divergence in research outputs between firms is large with many firms either well above or below the average. The results here are in line with Malerba and Orsenigo $(1995)^{10}$ where the Herfindahl indices, calculated using patent data, of electronic and chemical sectors are found to be high. Figure 4 illustrates the Herfindahl indices ${ }^{11}$ for our sample.

$$
\text { ** insert Figure } 4 \text { here }{ }^{* *}
$$

In general, an industry with Herfindahl index $(H H I)$ of 1,000 or above is considered concentrated. In contrast to an average score of 1,300 for the chemical sector reported by Malerba and Orsenigo (1995), we find a slightly smaller concentration ratio (an average of 934.86 over 1983-1997). Such a difference exists because the selection of firms in our sample tends to bias towards large firms. For the electronic and electrical industry, what we observe (an average of $1,284.89$ over 1983-1997) is very similar to the 1,300 obtained by Malerba and Orsenigo. It is important to note that COM has the highest score of $H H I$ in our sample, with an average of 1,970.2. The figure is so high because the heavyweights in this industry consist of two distinct types of firm: firms that are highly research oriented (e.g., IBM, Apple, SUN

\footnotetext{
${ }^{10}$ Instead of classifying firms into aggregate industries as in our paper, Malerba and Orsenigo (1995) divide firms from four European countries into 33 technological subclasses.

${ }^{11}$ Herfindahl Index is defined here as $H H I_{j, t}=\sum_{i}\left(P T_{i, j, t} / \sum_{i} P T_{i, j, t}\right)^{2}$.
} 
Microsystems, etc.) and firms that "clone" the product of others (e.g., Dell, Compaq, Fujitsu, etc.). For instance, the total revenue earned by Compaq is $38 \%$ of that earned by IBM in 1997, but the former was granted only 3 patents versus the 1,704 obtained by the latter in the same year. One last observation about the $H H I$ is the difference in the growth paths of the indices. The degree of concentration in the computer industry declines over time within the sample period while the opposite is true for the chemical industry.

Finally, from Figure 3(b), CHEM is witnessed to have the widest scope of innovations, COM the narrowest and EE in between. Apparently, fundamental innovations play a relatively important role in the development of the chemical industry compared to the other two. This is perhaps not a surprising result given the wide variety of chemical products our sample firms produce, including inorganic chemicals, organic chemicals, industrial chemicals, agricultural chemicals, drugs, and petrochemicals, etc.. Many of these products are used as producer goods or raw materials in other industries as well. Since fundamental innovations are more likely to be cited by other inventors, one would expect, in general, a positive relationship between patent scopes and forward citations ${ }^{12}$. We test this proposition by regressing the (log-transformed) forward citation to patent granted ratio ${ }^{13}$ at the industry level on

\footnotetext{
${ }^{12}$ An existing patent being cited by other inventors in future.

${ }^{13}$ More concisely, this is just $T F C_{j, t} / P T_{j, t}$ with $T F C_{j, t}$ being the industry aggregate of total foward citations.
} 
the (log-transformed) scope of innovations of $j$, i.e., $S O_{j, t}$ as defined in equation (6) but with the $i$ aggregated out. The regression is similar to what Lerner (1994) does to verify his measure of scope of innovations, and the OLS result is stated in colume two of Table 2.

$$
\text { ** insert Table } 2 \text { here }{ }^{* *}
$$

The standard OLS result shows signs of misspecification as evidenced from the small generalized Durbin-Watson statistic, see Appendix for details. We, therefore, try a regression with first difference in the dependent variable. As with the previous regression, the term $\ln P T_{j, t}$ on both sides are cancelled out with $\ln P T_{j, t-1}$ left on the right hand side as explanatory variable. This specification implies that the scope of innovation, as measured by the average number of USPC subclasses to which an industry's patents are assigned, is positively related to the growth in forward citations of those patents. As shown in column three of Table 2, such a relationship can indeed be established with all coefficients assuming the correct signs. The result is also statistically significant. As a final remark, it is worth noting that the coefficient for the time trend is negative due to the well known truncation problem common in citation statistics ${ }^{14}$.

\footnotetext{
${ }^{14}$ See Caballero and Adam (1993) for details.
} 


\section{CONCLUSION}

We device in this paper indices to measure different aspects of technological structure. The emphasis is laid on identifying sources of knowledge spillover and their impact on $R \& D$ activities. One salient feature of our work is that we make an effort to differentiate between spillover and technological overlap, even though the two could possibly be correlated. The need for so-doing stems from the fact that firms often cite patents of another origin or class of research, e.g., an automobile manufacturer may cite an innovation originated from a computer chips maker. Using our measure of technological overlap $(O L)$, we find that about $5 \%$ of the patents cited by the computer (COM) industry (excluding duplicates) were cited by at least two firms. The figures for the chemical (CHEM) and electronic and electrical (EE) industries are $3 \%$ and $4 \%$, respectively.

Regarding knowledge spillover, a convenient breakdown of the sources of spillover is available given the indices compiled. The intra-industry intensity of knowledge flow $(I F)$ captures the spillover due to innovations within the industy; the inter-industry intensity of knowledge flow $(E F)$ accounts for the impact due to other industries' reseach output; while cumulativeness $(C U)$ reflects the benefits of the acquired knowledge originated from in-house. We find that the contributions of these source are $12 \%, 73 \%$ and $15 \%$ for CHEM, $10 \%, 71 \%$ and $19 \%$ for COM, and $9 \%, 78 \%$ and $13 \%$ 
for EE. Thus, the three industries can internalize 15\%,19\% and 13\% respectively of their previous research efforts. Furthermore, the strong positive relationship found between $O L$ and $I F$ suggests that a larger degree of overlap induces a larger degree of intra-industry spillover, a result one would reasonably expect.

Another finding of this paper is that fundamental innovations are relatively more important in the development of the chemical industry compared to the other two. Since an innovation with a wider scope of application (measured by the number of USPC subclasses) is more likely to be cited in future, it can therefore be considered as more fundamental. We find a strong positive relationship between the scope of innovations and the growth in the number of forward citations.

In sum, the above results are consistent with the findings of previous studies in the literature. As pointed out by Jaffe (1988) and Griliches (1990), R\&D efforts are jointly determined by market conditions and technological opportunities. Investigation on market incentives to innovate is incomplete without considering the technological opportunities that characterize an industry. The different measures of technological structures proposed here could be combined with firm-level financial data to explore the relationship between market structure, technological structure and inventiveness. They should prove useful in explaining the differences in research incentives across industries, testing various existing theoretical models, and laying the ground-work for further theoretical research. 


\section{A APPENDIX}

\section{A.1 Firms in the sample}

\begin{tabular}{lll}
\hline Chemicals & Computers & Electronics \& \\
$(\mathbf{C H E M})$ & $(\mathbf{C O M})$ & Electricals (EE) \\
\hline Air Products and Chemicals & Acer & AMP \\
Akzo Nobel & Advanced Digital Information & Aiwa \\
Asahi Chemical & Alanco & Alba \\
Ascot & Ampex & American Technology \\
ATOFINA & Apple Computer & Anam Electronics \\
Balchem & Auspex Systems & Applica Incorporated \\
BASF & Cadence Design Systems & Bang \& Olufsen \\
Bayer AG & Cambex & BISSELL \\
Bush Boake Allen & Canon & Brasmotor S.A. \\
Cabot Microelectronics & Ceridian & BRITA GmbH \\
Cambrex & Ciprico & Cobra Electronic \\
Cambridge Isotope Lab. & CMD Technologies & Conair \\
Clean Diesel Tech. & Compaq Computer & Curtis International \\
CP Kelco ApS & Computer Associates Intl. & Daewoo Electronics \\
Dainippon Ink and Chemical & Cray & Electrolux L.L.C. \\
Dow Chemical & Data General & Emerson \\
\hline & & \\
\hline
\end{tabular}




\begin{tabular}{|c|c|c|}
\hline CHEM & $\mathrm{COM}$ & $\mathbf{E E}$ \\
\hline DSM N.V. & Dell Computer & Fantom Technologies \\
\hline DuPoint & Diamond Flower Electric & Fedders \\
\hline Eastman Chemical & Drexler Technology & Gaggia S.p.A. \\
\hline Ecolab & ECCS & General Electric \\
\hline Energia e Indust. Aragonesas & eMachines & Global-Tech \\
\hline Engelhard & EMC & Goodman \\
\hline FMC & Exabyte & Great Wall Cybertech \\
\hline Gantrade & Gateway & Harman Int'l Industries \\
\hline Genencor Intl. & Headway & Harris \\
\hline Giovanni Crespi S.p.A. & Hewlett-Packard & Hitachi \\
\hline Henkel & Imation & HMI Industries \\
\hline Hercules & Immecor & Holmes \\
\hline Hoechst & Intl. Business Machines & Honeywell \\
\hline Huntsman Corp. & Iomega & Kenwood \\
\hline ICC Industries & Komag & Kirby \\
\hline ICI Americas & Learning Technology & Koss \\
\hline Imperial Chemical Industries & Legend & Krell Industries \\
\hline LaRoche Industries & Lexmark Intl. & Lakewood Engin. \& Mfg. \\
\hline
\end{tabular}




\begin{tabular}{|c|c|c|}
\hline CHEM & COM & EE \\
\hline Lonza & LinuxForce & LG Electronics \\
\hline LSB Industries & LSC & Lifetime Hoan \\
\hline Lubrizol & Maxtor & Litton Industries \\
\hline Melamine Chemicals & Medion & Maax \\
\hline Millennium Chemicals & Micron Electronic & MartinLogan \\
\hline Minnesota Mining and Mfg. & Microsoft & Matsushita Electric \\
\hline Mitsubishi Chemical & MiTAC & Maytag \\
\hline Mitsubishi Rayon & M-Systems Flash Disk & Merloni Elettrodom. S.p.A. \\
\hline Mitsui Chemicals & MTI Technology & Minuteman Intl. \\
\hline Monsanto & Mylex & Monotub Industries \\
\hline Montedison & NCR & Moulinex \\
\hline Nalco Chemical & nCUBE & Multibras S.A. Electrodom. \\
\hline Olin & Network Appliance & NEC \\
\hline OM Group & Network Engines & Norcom Electronics \\
\hline Orgasynth & Olidata S.p.A. & Philips Electronics \\
\hline Orica & Oracle & Phoenix Gold Intl. \\
\hline Philipp Brothers Chemicals & Palm & Pioneer \\
\hline PPG Industries & Perisol Technology & Polk Audio \\
\hline
\end{tabular}




\begin{tabular}{|c|c|c|}
\hline CHEM & $\mathrm{COM}$ & EE \\
\hline Praxair & Phase Metrics & Raychem \\
\hline Produits Chimiques Auxiliaires & Pinnacle Micro & Recoton \\
\hline Rhone-Poulene & Pitney Bowes & Remington Products \\
\hline Rohm \& Haas & Procom Technology & Rockford \\
\hline Scapa Group & Qualstar & Royal Appliance Mfg. \\
\hline Sherwin-Williams & Quantum & Samsung Electronics \\
\hline Shin-Etsu Chemical & Ricoh & Sanyo \\
\hline Sinopec Shanghai Petrochemical & RM plc & SDI Technologies \\
\hline Snia S.p.A. & Seagate Technology & Sensory Science \\
\hline Societe d'Oxygene et d'Acetylene & Silicon Graphics & Serial System \\
\hline Solutia & Single Source Systems & Sharp \\
\hline Solvay S.A. & Singlepoint Systems & Siemens \\
\hline The BOC Group & SteelCloud & Smith Corona \\
\hline Tosoh & StorageApps & Sony \\
\hline Trans-Resources & StorageTechnology & SPX \\
\hline Ube Industries & SUN Microsystems & Sunbeam \\
\hline Union Carbide & The New Internet Computer & Thakral \\
\hline W.R. Grace \& Co. & TriGem Computer & Thomas \& Betts \\
\hline
\end{tabular}




\begin{tabular}{ll}
\hline CHEM & EEM \\
\hline Unisys & THOMSON multimedia \\
U-tron Technologies & Tilia \\
VA Linux Systems & Universal Electronics \\
Vicinity Systems & Water Pik Technologies \\
Vitech America & Whirlpool \\
Vobis Microcomputer AG & White Consolidated Indust. \\
Xerox & Zenith Electronics \\
\hline
\end{tabular}

\section{A.2 Transformation of variables}

Bharvaga et al. (1982) suggests generalizing the Durbin-Watson statistic to panel data ( $N$ individuals and $T$ periods) by defining

$$
d_{P}=\frac{\sum_{i=1}^{N} \sum_{t=1}^{T}\left(\widetilde{u}_{i t}-\widetilde{u}_{i t-1}\right)^{2}}{\sum_{i=1}^{N} \sum_{t=1}^{T} \widetilde{u}_{i t}^{2}}
$$

where $\widetilde{u}_{i t}(i=1, \cdots, N ; t=1, \cdots, T)$ are the OLS residuals from estimating a fixedeffects model with $\mathrm{AR}(1)$ disturbance term, i.e. $y_{i t}=\delta_{i}+X_{i t} \gamma+u_{i t} ; u_{i t}=\rho u_{i t}+e_{i t}$; $(i=1, \cdots, N ; t=1, \cdots, T)$ with $X_{i t}$ and $\gamma$ of dimensions $1 \times n$ and $n \times 1$ respectively. $\delta_{i}$ are the individual specific dummies. Once $d_{P}$ is obtained, a preliminary estimate of the $\operatorname{AR}(1)$ coefficient can be calculated using $\rho_{D}=1-d_{P} / 2$. One can then solve

$$
\rho_{D}=1-\frac{(1-\rho)(T-1)}{\left[T-\frac{1+\rho}{1-\rho}+\frac{2 \rho\left(1-\rho^{T}\right)}{T(1-\rho)^{2}}\right]}
$$


iteratively for $\rho$.

If the $\widehat{\rho}$ so estimated is statistically different from 0 (and 1$)^{15}$, the following transformation is carried out before running the regression:

1. $\left(1-\rho^{2}\right)^{1 / 2} y_{i 1}=\left(1-\rho^{2}\right)^{1 / 2} \delta_{i}+\left(1-\rho^{2}\right)^{1 / 2} X_{i 1} \gamma+e_{i 1} \quad(i=1, \cdots, N)$

2. $y_{i t}-\rho y_{i t-1}=(1-\rho) \delta_{i}+\left(X_{i t}-\rho X_{i t-1}\right) \gamma+e_{i t} \quad(i=1, \cdots, N ; t=2, \cdots, T)$

3. Eliminate the $\delta_{i}$ using $C^{+}=I_{N} \otimes C^{*}$ where $C^{*}=I_{T}-w\left(w^{\prime} w\right)^{-1} w^{\prime}$ and $w^{\prime}$ is a $T \times 1$ vector $\left(\left(1-\rho^{2}\right)^{1 / 2}, 1-\rho, \cdots, 1-\rho\right)$.

\footnotetext{
${ }^{15}$ The case of unit root disturbance is treated separetely from the stationary case. The critical values for both scenarios can be found in Bharvaga et al. (1982).
} 


\section{References}

[1] Aghion, P., Harris, C. and Vickers, J. (1995) Competition and Growth with Step-by-step Technological Progress, Mimeo.

[2] Bhargava, A.,Franzini, L. and Narendranathan, W. (1982) Serial Correlation and Fixed Effects Model. Review of Economic Studies, 49, 533-549.

[3] Caballero, R.J. and Jaffe, A.B. (1993) How High are the Giants' Shoulders: An Empirical Assessment of Knowledge Spillovers and Creative Destruction in a Model of Economic Growth. In Blanchard O.J. and Fischer S., eds., NBER Macroeconomics Annual 1993. Cambridge and London: MIT Press, 15-74.

[4] Griliches, Z. (1990) Patent Statistics as Economic Indicators: A Survey. Journal of Economic Literature, 28(4), 1661-1707.

[5] Jaffe, A. (1988) Demand and Supply Influences in R\&D Intensity and Productivity Growth. The Review of Economics And Statistics. 70(3), 431-437.

[6] Jaffe, A., Trajtenberg, M. and Henderson, R. (1993) Geographic Localization of Knowledge Spillovers as Evidenced by Patent Citations. Quarterly Journal of Economics, 108(3), 577-598.

[7] Jaffe, A., Trajtenberg, M. and Fogarty, M. (2000) Knowledge Spillovers and 
Patent Citations: Evidence from a Survey of Inventors. American Economic Review, 90(2), 215-218.

[8] Lanjouw, J.O. and Schankerman, M. (1999) The Quality of Ideas: Measuring Innovation with Multiple Indicators. NBER Working Paper 7345.

[9] Lerner, J. (1994) The Importance of Patent Scope: An Empirical Analysis. RAND Journal of Economics, 25(2), 319-333.

[10] Malerba, F. and Orsenigo, L. (1995) Schumpeterian Patterns of Innovation. Cambridge Journal of Economics, 19, 47-65.

[11] Mátyás, L. and Sevestre, P., eds. (1996) The Econometrics of Panel Data: A Handbook of the Theory with Applications. Dordrecht: Kluwer Academic Publishers.

[12] Scherer, F.M. (1981) Using Linked Patent and R\&D Data to Measure InterIndustry Technology Flows. In: Griliches Z., eds., R\&D, Patents, and Productivity. Chicago: University Of Chicago Press for NBER, 417-464.

[13] Schmookler, J. (1966) Invention and Economic Growth. Cambridge: Harvard University Press.

[14] USPTO (1997) Patenting by Organizations. U.S. Patent and Trademark Office: Office of Electronic Information Product/ TAF Program. 
[15] USPTO (2000) All Technologies Report. U.S. Patent and Trademark Office: Office of Electronic Information Product/ TAF Program. 
Table 1. OLS results of regressing $\ln I F_{j, t}$ on $\ln O L_{k=2, j, t}$

\begin{tabular}{|c|c|c|c|c|}
\hline Variables / Parameters & \multicolumn{2}{|c|}{ OLS - standard } & \multicolumn{2}{|c|}{ OLS - transformed ${ }^{\mathrm{a}}$} \\
\hline Dependent Variable & \multicolumn{2}{|c|}{$\ln B C_{j, t}$} & \multicolumn{2}{|c|}{$\ln B C_{j, t}$} \\
\hline Regressors & Coefficient & $t$-values & Coefficient & $t$-values \\
\hline TimeTrend & 0.0658 & $(16.1881)$ & 0.0654 & $(17.5883)$ \\
\hline $\operatorname{Dummy}_{j=1}(\mathrm{CHEM})$ & 3.6915 & $(22.7345)$ & 3.6839 & $(24.7019)$ \\
\hline $\operatorname{Dummy}_{j=2}(\mathrm{COM})$ & 3.2346 & $(18.3838)$ & 3.2254 & $(19.9666)$ \\
\hline $\operatorname{Dummy}_{j=3}(\mathrm{EE})$ & 3.3457 & $(18.8960)$ & 3.3368 & $(20.5127)$ \\
\hline $\ln C P_{k=2, j, t}$ & 0.5630 & $(19.6716)$ & 0.5646 & $(21.4774)$ \\
\hline$\widehat{\sigma}$ & 0.0046 & & 0.0043 & \\
\hline$\hat{\rho}^{\mathrm{b}}$ & -0.0794 & & n.a. & \\
\hline$R^{2}$ & 0.9889 & & 0.9923 & \\
\hline Durbin-Watson statistic & 2.2944 & & n.a. & \\
\hline Generalized DW statistic $^{c}$ & 2.1377 & & 1.9438 & \\
\hline
\end{tabular}

Remarks:

a. Transformation is done as suggested by Bhargava et al. (1982). See Appendix.

Note that $\ln P T_{j, t}$ on both sides are cancelled out before running the regression.

b. Coefficient of lag term in $\mathrm{AR}(1)$ error specification.

c. Generalized version of DW statistic adapted for panel data models. 
Table 2. OLS results of regressing $\ln \left(T F C_{j, t} / P T_{j, t}\right)$ on $\ln S O_{j, t}$

\begin{tabular}{|c|c|c|c|c|}
\hline Variables / Parameters & \multicolumn{2}{|c|}{ OLS - standard } & \multicolumn{2}{|c|}{ OLS - differenced ${ }^{\mathrm{a}}$} \\
\hline Dependent Variable & \multicolumn{2}{|c|}{$\ln T F C_{j, t}$} & \multicolumn{2}{|c|}{$\ln T F C_{j, t}-\ln T F C_{j, t-1}$} \\
\hline Regressors & Coefficient & $t$-values & Coefficient & $t$-values \\
\hline TimeTrend & -0.1400 & $(-9.2320)$ & -0.0489 & $(-7.0456)$ \\
\hline Dummy $_{j=1}($ CHEM $)$ & -7.6075 & $(-3.7491)$ & -3.3594 & $(-3.6721)$ \\
\hline $\operatorname{Dummy}_{j=2}(\mathrm{COM})$ & -5.7546 & $(-3.0171)$ & -2.8328 & $(-3.2993)$ \\
\hline $\operatorname{Dummy}_{j=3}(\mathrm{EE})$ & -6.6297 & $(-3.2732)$ & -3.0212 & $(-3.3250)$ \\
\hline $\ln \left(\sum_{i}\left(\sum_{s} C O_{s, i, j, t}\right)\right)$ & 1.8519 & $(8.5405)$ & 0.8404 & $(4.6910)$ \\
\hline $\ln P T_{j, t-1}$ & n.a. & n.a. & -0.5736 & $(-3.3633)$ \\
\hline$\widehat{\sigma}$ & 0.0636 & & 0.0106 & \\
\hline$\hat{\rho}^{\mathrm{b}}$ & 0.8655 & & n.a. & \\
\hline$R^{2}$ & 0.8410 & & 0.7442 & \\
\hline Durbin-Watson statistic & 0.7087 & & n.a. & \\
\hline Generalized DW statistic $^{\mathrm{c}}$ & 0.5556 & & 1.7505 & \\
\hline
\end{tabular}

Remarks:

a. Differencing is performed on the dependent variable only. The term $\ln P T_{j, t}$ on both sides of the regression equation are cancelled out.

b. Coefficient of lag term in $\mathrm{AR}(1)$ error specification.

c. Generalized version of DW statistic adapted for panel data models. 
Figure 1: Two-firm and Three-firm Common Citation Indices

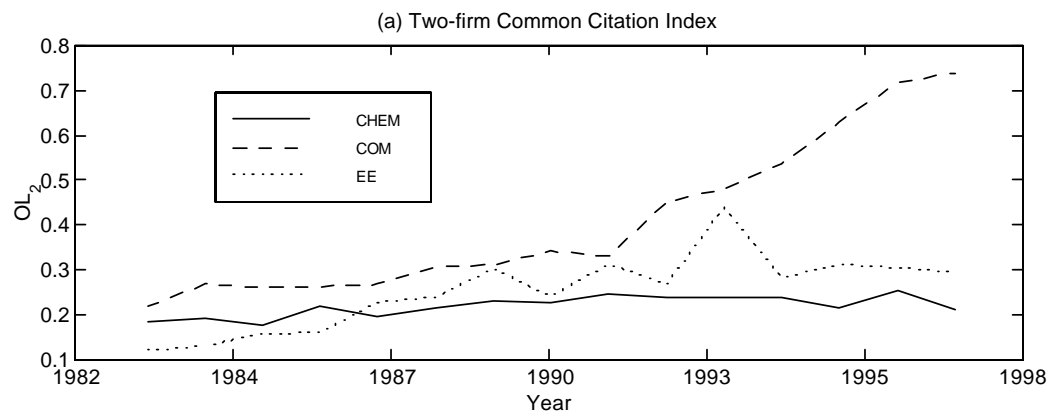

(b) Three-firm Common Citation Index

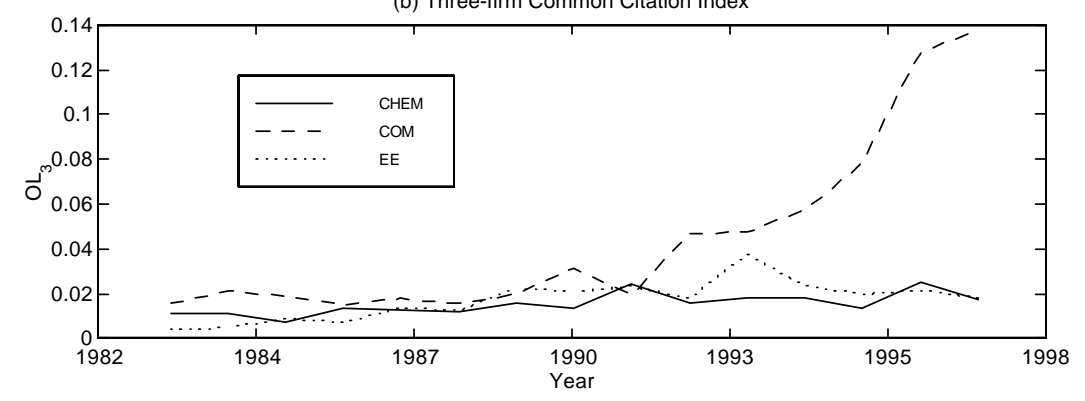


Figure 2: Intra-industry Intensity of Knowledge Flow and Cumulativeness

(a) Intra-industry Intensity of Knowledge Flow

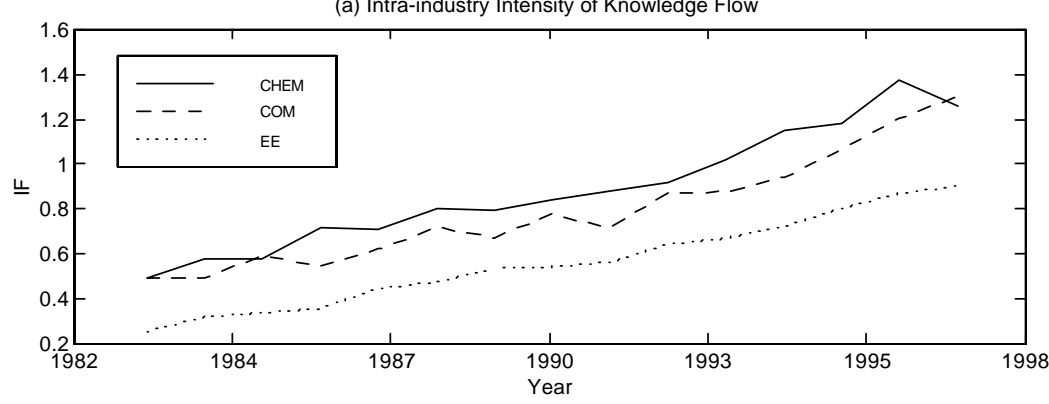

(b) Average Cumulativeness

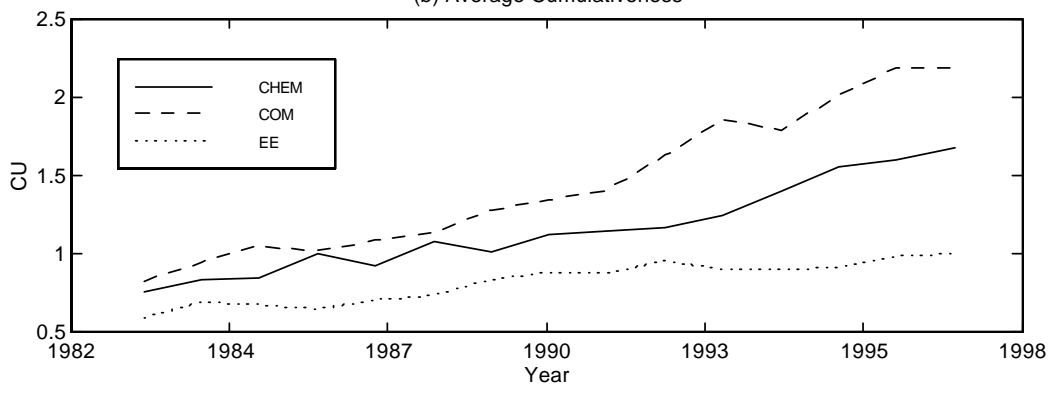


Figure 3: Technology Level Homogeneity and Scope of Innovations
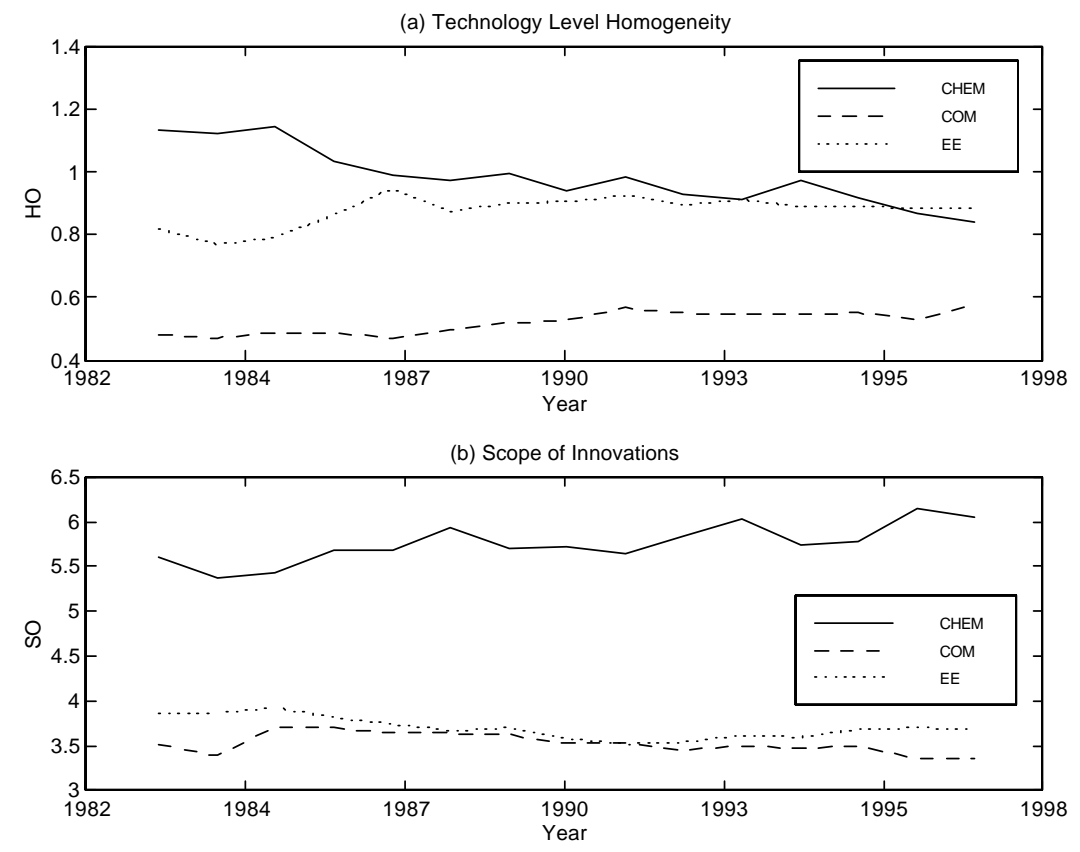
Figure 4: Herfindahl Indices based on Number of Patents

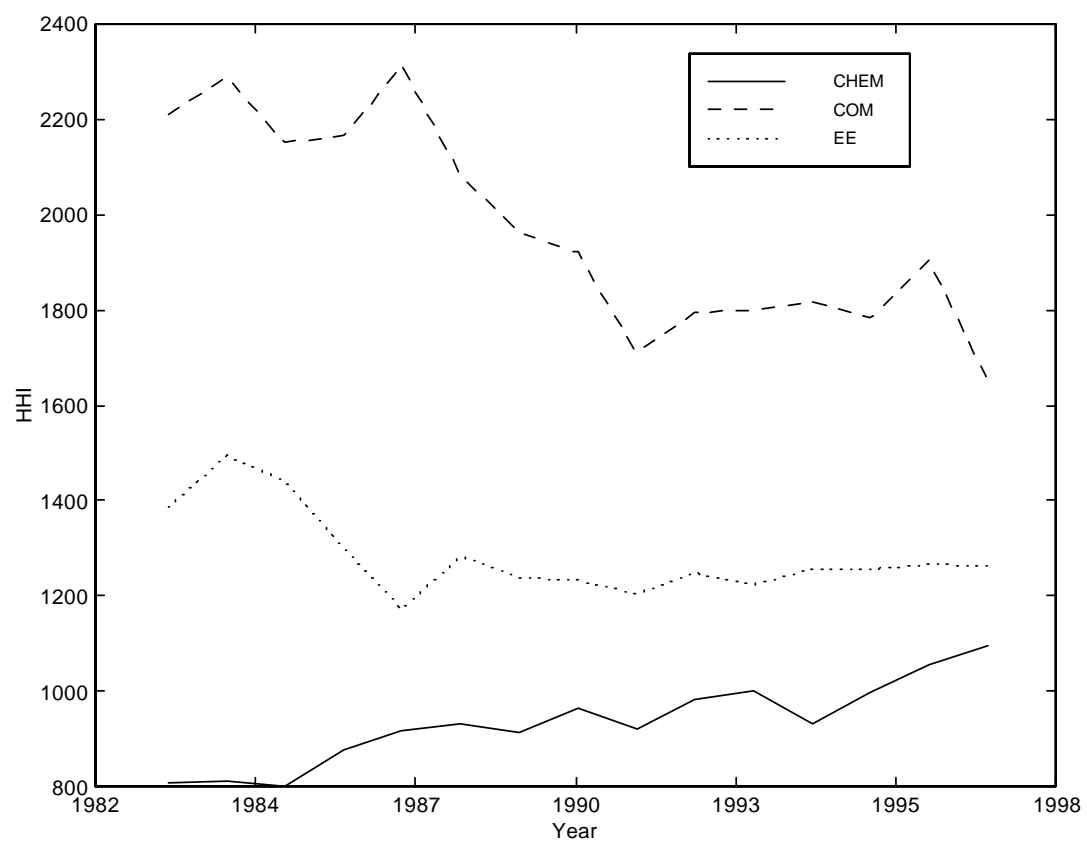

